\title{
Nocardia niwae sp. nov., isolated from human pulmonary sources
}

\author{
Benjamin D. Moser, ${ }^{1}$ Hans-Peter Klenk, ${ }^{2}$ Peter Schumann, ${ }^{2}$ \\ Gabriele Pötter, ${ }^{2}$ Brent A. Lasker, ${ }^{1}$ Arnold G. Steigerwalt, ${ }^{1}$ \\ Hans P. Hinrikson ${ }^{1}$ and June M. Brown ${ }^{1}$ \\ ${ }^{1}$ Bacterial Zoonoses Branch, Division of Foodborne, Bacterial and Mycotic Diseases, National \\ Center for Zoonotic, Vector-borne and Enteric Diseases, Centers for Disease Control and \\ Prevention, Atlanta, GA 30333, USA \\ ${ }^{2}$ German Collection of Microorganisms and Cell Cultures, Braunschweig, Germany
}

Correspondence Benjamin D. Moser ghn5@cdc.gov

\begin{abstract}
Members of the genus Nocardia are responsible for cutaneous, pulmonary and disseminated human infections. From 2003 to 2008, four nocardioform strains (W8027, W8681, W9071 and W9241 ${ }^{\top}$ ) were isolated from patients in the state of Florida, USA. Ribosomal gene sequencing analysis suggested that a novel species of the genus Nocardia had been isolated. These strains were subjected to a taxonomic analysis using a polyphasic approach. Phenotypic analyses included morphological examination, biochemical profiling and antimicrobial susceptibility testing. Molecular studies included 16S rRNA and DNA gyrase B subunit ( $g y r B$ ) gene sequence analyses and DNA-DNA hybridization. Phylogenetic neighbours were determined through 16S rRNA and gyrB gene sequence analyses. Phenotypic characteristics that differentiated the novel isolates from phylogenetically related species were growth at $45^{\circ} \mathrm{C}$, and three of the four novel strains utilized L-rhamnose. The antimicrobial profiles could not reliably distinguish the novel species from related nocardiae. Analysis showed that the $16 \mathrm{~S}$ rRNA gene sequences of the four novel isolates were identical. The BLAST analysis of the near full-length 16S rRNA gene showed $99.2 \%$ sequence similarity to Nocardia araoensis DSM $44729^{\top}$, Nocardia arthritidis DSM $44731^{\top}$ and Nocardia beijingensis JCM $10666^{\top}$, $98.7 \%$ to Nocardia amamiensis DSM $45066^{\top}, 98.2 \%$ to Nocardia pneumoniae JCM $12119^{\top}$ and $97.8 \%$ to Nocardia takedensis JCM $13313^{\top}$. Analysis of partial gyrB gene sequences showed that the novel isolates had $95.4 \%$ similarity to $N$. arthritidis DSM $44731^{\top}, 95.3 \%$ to Nocardia gamkensis DSM $44956^{\top}, 94.4 \%$ to N. pneumoniae JCM $12119^{\top}, 93.8 \%$ to Nocardia asiatica DSM $44668^{\top}, 93.5 \%$ to $N$. amamiensis DSM $45066^{\top}$, $93.4 \%$ to $N$. beijingensis JCM $10666^{\top}$ and $93.2 \%$ to $N$. araoensis DSM $44729^{\top}$. The DNA-DNA relatedness values between the four novel strains were $86-89 \%$; the relatedness value for strain W9241 ${ }^{\top}$ compared with $N$. beijingensis JCM $10666^{\top}$ was $47 \%$ and $46 \%$ with $N$. araoensis DSM $44729^{\top}, 44 \%$ with $N$. arthritidis DSM $44731^{\top}, 32 \%$ with $N$. amamiensis DSM $45066^{\top}$ and $20 \%$ with $N$. asiatica DSM $44668^{\top}$. The results of the taxonomic analysis suggested that the new isolates represent a novel species of the genus Nocardia for which the name Nocardia niwae sp. nov. is proposed. The type strain is $\mathrm{W} 9241^{\top}\left(=\mathrm{DSM} 45340^{\top}=\right.$ CCUG $\left.57756^{\top}\right)$.
\end{abstract}

Species of the genus Nocardia are ubiquitous environmental pathogens that cause a variety of different

Abbreviation: MIC, minimum inhibitory concentrations.

The GenBank/EMBL/DDBJ accession numbers for the $16 \mathrm{~S}$ rRNA gene sequences for Nocardia niwae sp. nov. isolates W8027, W8681, W9071 and $W_{9241^{\top}}$ are FJ765053, FJ765054, FJ765055 and FJ765056, respectively. The accession numbers for the gyr $B$ gene sequences for $N$. niwae isolates W8027, W8681, W9071 and W9241 ${ }^{\top}$ are FJ765057, FJ765058, FJ765059 and FJ765060, respectively.

Supplementary figures and supplementary tables are available with the online version of this paper. disease manifestations in humans and animals. Members of the genus Nocardia have been identified as the source of non-specific pulmonary, extrapulmonary, cutaneous and catheter-related infections in humans (Brown-Elliott et al., 2006). Since members of the genus Nocardia do not present definitive clinical manifestations, nocardial infections associated with humans and animals are difficult to diagnose (Gordon et al., 1974; Boiron et al., 1992; Goodfellow, 1998) and Nocardia species are challenging to identify phenotypically (Conville \& Witebsky, 2007). However, during the last ten years, with the advent of molecular techniques, the genus Nocardia has undergone 
many taxonomic changes (Roth et al., 2003). Current methods of classification of species of the genus Nocardia investigate not only morphological, biochemical and chemotaxonomic characteristics, but also include phylogenetic analyses and DNA-DNA hybridization (Stackebrandt et al., 2002).

In this paper, the morphological, biochemical and chemotaxonomic characteristics along with analyses of the 16S rRNA and gyrB gene sequences and DNA-DNA hybridization are reported for four isolated strains of the genus Nocardia. As part of a taxonomic analysis based on a polyphasic approach, these four strains were compared by $16 \mathrm{~S}$ rRNA gene sequence analysis with neighbouring reference strains of the genus Nocardia in order to characterize a novel species.

From 2003 to 2008, four clinical strains were sent to the Special Bacteriology Reference Laboratory (SBRL) at the Centers for Disease Control and Prevention (CDC) in Atlanta, Georgia, USA. The four strains examined (W8027, W8681, W9071 and W9241 ${ }^{\mathrm{T}}$ ) were isolated from clinical pulmonary sources and were initially identified as a putative novel species of the genus Nocardia through 16S rRNA gene sequence analysis. Strains W8681 and W9071 were isolated from bronchial washings of a 37-year-old female and a 92year-old female, respectively. The remaining two strains, W8027 and W9241 ${ }^{\mathrm{T}}$, were isolated from a pleural mass aspirate of a 72-year-old female and a lung biopsy of a 60year-old male, respectively. All four strains originated from individuals residing in the state of Florida, USA.

The morphological features of these Nocardia strains were studied from aerobic growth on heart infusion agar with rabbit blood (BBL) and Middlebrook 7H11 agar slants (Remel) for 7 days at $35{ }^{\circ} \mathrm{C}$ (Brown-Elliott et al., 2006). The organisms were aerobic, Gram-positive and weakly acid-fast by modified Kinyoun stain (Berd, 1973). They formed colonies with white aerial and substrate hyphae on rabbit blood media and orange-coral-coloured hyphae on Middlebrook 7H11 media after 7 days at $35{ }^{\circ} \mathrm{C}$; the reverse side was also orange-coral-coloured on Middlebrook agar. The phenotypic characteristics of the strain designated as the type strain, $\mathrm{W} 9241^{\mathrm{T}}$, are given in the species description and were determined using methods described previously by Berd (1973).

Tests for the utilization of 22 carbohydrates, production of arylsulfatase, decomposition of adenine, aesculin, casein, hypoxanthine, tyrosine and xanthine, utilization of acetamide, citrate and urea, nitrate reduction, growth in lysozyme and growth at 25,35 and $45{ }^{\circ} \mathrm{C}$ were conducted according to previously described methods (Berd, 1973; Conville \& Witebsky, 2007). The phenotypic characteristics that could be used to differentiate strains W8027, W8681, W9071 and $\mathrm{W} 9241^{\mathrm{T}}$ and the type strains of phylogenetically related species of the genus Nocardia are presented in Table 1.

The minimum inhibitory concentrations (MIC) for ten antimicrobial agents: amikacin, amoxicillin/clavulanate,
Table 1. Differential phenotypic characteristics of strains W8027, W8681, W9071, W9241 ${ }^{\top}$ and some phylogenetically related type strains

Strains: 1, W8027; 2, W8681; 3 W9071; 4, W9241 ${ }^{\mathrm{T}} ; 5$, N. amamiensis DSM $45066^{\mathrm{T}} ; 6, N$. arthritidis DSM $44731^{\mathrm{T}} ; 7, N$. asiatica DSM $44668^{\mathrm{T}} ; 8, N$. beijingensis JCM $10666^{\mathrm{T}}$. All strains utilized citrate, Dglucose, glycerol and trehalose and were resistant to lysozyme. Strains did not utilize adonitol, L-arabinose, $i$-erythritol, D-galactose, lactose, D-mannitol, D-sorbitol or D-xylose. All strains grew at 25 and $35{ }^{\circ} \mathrm{C}$ and were unable to hydrolyse adenine, hypoxanthine, tyrosine and xanthine. All strains lacked arylsulfatase activity. -, Negative; + , positive.

\begin{tabular}{|c|c|c|c|c|c|c|c|c|}
\hline Characteristic & 1 & 2 & 3 & 4 & 5 & 6 & 7 & 8 \\
\hline \multicolumn{9}{|l|}{ Utilization as carbon source: } \\
\hline Cellobiose & - & - & - & - & - & + & - & - \\
\hline Dulcitol & - & - & - & - & - & - & + & - \\
\hline D-Fructose & - & - & - & - & + & + & - & + \\
\hline myo-Inositol & - & - & - & - & + & + & - & - \\
\hline Maltose & - & - & - & + & + & + & + & + \\
\hline Mannose & - & - & - & - & + & + & - & - \\
\hline Melibiose & - & - & - & - & - & + & - & - \\
\hline Raffinose & - & - & - & - & - & + & - & - \\
\hline L-Rhamnose & + & + & - & + & - & - & + & - \\
\hline Salicin & - & - & - & - & - & + & - & - \\
\hline Sucrose & + & + & - & + & - & + & - & + \\
\hline Nitrate reduction & + & + & + & + & - & - & + & + \\
\hline \multicolumn{9}{|c|}{ Utilization as carbon and nitrogen source: } \\
\hline Acetamide & - & - & - & - & - & - & - & + \\
\hline \multicolumn{9}{|l|}{ Hydrolysis of: } \\
\hline Aesculin & - & - & - & - & - & - & + & - \\
\hline Urea & + & + & - & + & + & + & + & - \\
\hline $\begin{array}{l}\text { Growth on heart infusion agar at } \\
45^{\circ} \mathrm{C}\end{array}$ & + & + & + & + & - & + & - & - \\
\hline
\end{tabular}

ceftriaxone, ciprofloxacin, clarithromycin, imipenem, linezolid, minocycline, tigecycline and trimethoprim/sulfamethoxazole were determined using panels from PML Microbiologicals, Inc. following guidelines and breakpoints established for members of the genus Nocardia (NCCLS, 2003). The results of the antimicrobial susceptibility testing indicated that the four clinical strains were susceptible to amikacin, ceftriaxone, clarithromycin, linezolid, minocycline and trimethoprim/sulfamethoxazole. All strains showed resistance to amoxicillin/clavulanate and varied in their resistance to ciprofloxacin. The results for the four novel strains and the type strains of related species are presented in Supplementary Table S1 (available in IJSEM Online).

Analyses of diaminopimelic acid isomers were performed according to the methods described by Rhuland et al. (1955). Following the methods of Minnikin et al. (1984), a small-scale integrated procedure was used to extract and purify quinones and polar lipids. A $200 \mu \mathrm{l}$ aliquot of 2 propanol was used to dissolve the preparations and $1-10 \mu \mathrm{l}$ aliquots, without further purification, were separated 
through HPLC and analysed as described by Kroppenstedt (1982, 1985). Extracted polar lipids were examined through two-dimensional TLC and identified according to Minnikin et al. (1977). The Microbial Identification System (MIDI Inc.) for GC analyses (Sasser, 1990) was utilized for the analysis of fatty acid methyl esters and mycolic acid trimethylsilyl esters prepared as described by Klatte et al. (1994). The properties of the novel strains were chemotaxonomically consistent with those expected for members of the genus Nocardia (Kämpfer et al., 2004). The fatty acid patterns of the novel strains are presented in Supplementary Table S2 (see IJSEM Online). Whole cell hydrolysates of strain $\mathrm{W} 9241^{\mathrm{T}}$ contained meso-diaminopimelic acid as the diagnostic amino acid of the cell-wall peptidoglycan. The major cell-wall sugars were arabinose, galactose, glucose and ribose; mannose, xylose and rhamnose were not present. MK-8 $\left(\mathrm{H}_{4 \mathrm{cyc}}\right)$ was the major quinone for this strain. The polar lipids present were phosphatidylinositol mannoside, phosphatidylinositol, phosphatidylethanolamine and diphosphatidylglycerol. These corresponded with lipids reported previously for members of the genus Nocardia by Minnikin et al. (1977). The fatty acid patterns of the four novel strains were of straight chain saturated and unsaturated fatty acids plus tuberculostearic acid. Mono- and di-unsaturated mycolic acids ranged from 50-60 carbon atoms, as consistent with chain length expected for members of the genus Nocardia (Klatte et al., 1994; Baba et al., 1997). The G + C content of the DNA of strain $\mathrm{W} 9241^{\mathrm{T}}$ was determined by HPLC as described by Mesbah et al. (1989). The G+C value of $68.5 \mathrm{~mol} \%$ was within the range of the DNA base composition previously reported for members of the genus Nocardia (Goodfellow \& Maldonado, 2006).

Almost complete 16S rRNA gene sequences (1441 bp) were determined for the four novel strains and amplification of the 16S rRNA gene was performed as described by Morey et al. (2006) except for the modification of primers FL1
(5'-CCGAATTCGTCGACA) and RL1 (5'-CCCGGGATCCAAGCT). BLAST software (nucleotide-nucleotide BLAST: https://www.ncbi.nlm.nih.gov/BLAST) was used to identify related sequences in GenBank. Bootstrap analysis with 1000 replicates was performed using MEGA4 software to assess the support for each node of the phylogenetic tree (Tamura et al., 2007). The 16S rRNA gene sequences for the four novel strains were identical. The phylogenetically related neighbours of the novel strains (Fig. 1) were Nocardia araoensis DSM $44729^{\mathrm{T}}$ (99.2\% similarity), $N$. arthritidis DSM $44731^{\mathrm{T}}(99.2 \%)$ and N. beijingensis JCM $10666^{\mathrm{T}}$ $(99.2 \%), \quad N$. amamiensis DSM $45066^{\mathrm{T}}(98.7 \%), \quad N$. pneumoniae JCM $12119^{\mathrm{T}}(98.2 \%)$ and $N$. takedensis JCM $13313^{\mathrm{T}}(97.8 \%)$.

DNA extraction, amplification of a 1245-bp gyrB gene fragment, primers and sequencing followed methods previously described by Shen et al. (2006). The MEGA4 program was used for phylogenetic assessment (Tamura et al., 2007). The gyrB gene sequences for the four novel strains were identical. The closest phylogenetic neighbours were revealed (Fig. 2) as N. arthritidis DSM $44731^{\mathrm{T}}(95.4 \%$ similarity), $N$. gamkensis DSM $44956^{\mathrm{T}}(95.3 \%), \quad N$. pneumoniae JCM $12119^{\mathrm{T}}(94.4 \%), \quad N$. asiatica DSM $44668^{\mathrm{T}}(93.8 \%)$, N. amamiensis DSM $45066^{\mathrm{T}}$ (93.5\%), N. beijingensis JCM $10666^{\mathrm{T}}(93.4 \%)$ and N. araoensis DSM $44729^{\mathrm{T}}(93.2 \%)$.

DNA was extracted from the four novel strains and from five closely related phylogenetic neighbours as described by Loeffelholz \& Scholl (1989) and DNA-DNA hybridization studies were performed in the Special Bacteriology Reference Laboratory at CDC following the protocol by Brenner et al. (1982). DNA-DNA hybridization studies were performed between DNA samples from strains W8027, W8681, W9071 and W9241 ${ }^{\mathrm{T}}$ as well as between the DNA of strain W9241 ${ }^{\mathrm{T}}$ and five of the most closely phylogenetically related members of the genus Nocardia.

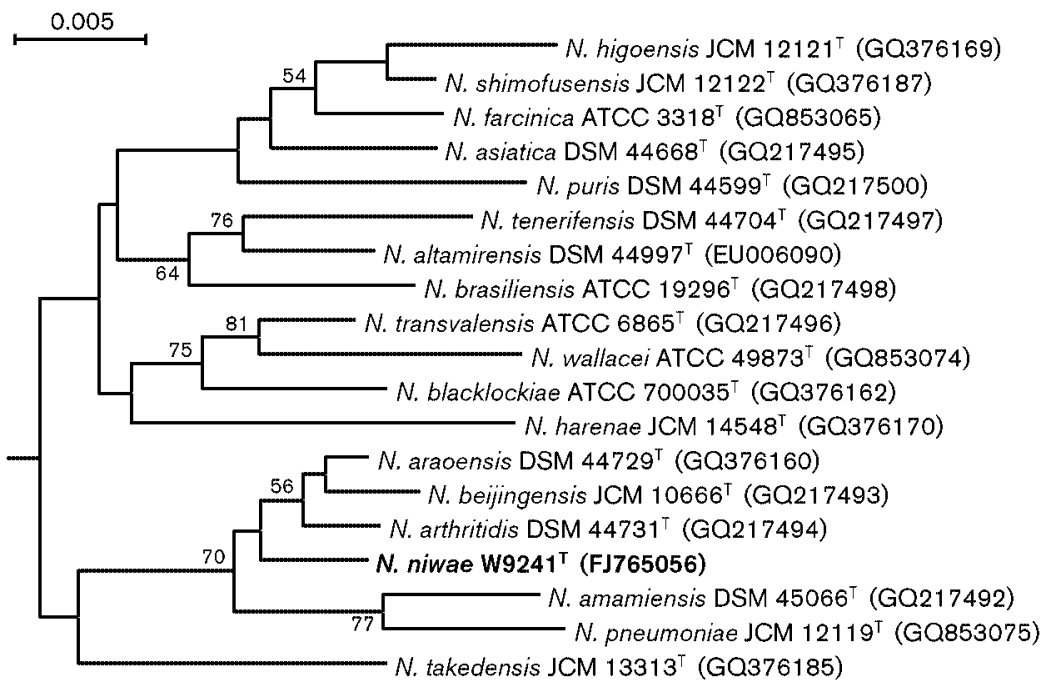

Fig. 1. Phylogenetic tree, based on $16 \mathrm{~S}$ rRNA gene sequences, showing the relationships of strain $\mathrm{W} 9241^{\top}$ and a few closely related Nocardia species. The tree was constructed using the neighbour-joining method and was based on a comparison of $\sim 1441 \mathrm{nt}$. The tree was rooted using Mycobacterium tuberculosis ATCC $27294^{\top}$ as the outgroup (not shown). Bootstrap percentages were expressed as percentages of 1000 replicates and only values $>50 \%$ are presented. Bar, 0.005 substitutions per nucleotide position. The full tree from which this area is taken is available as Supplementary Fig. S1 in IJSEM Online. 


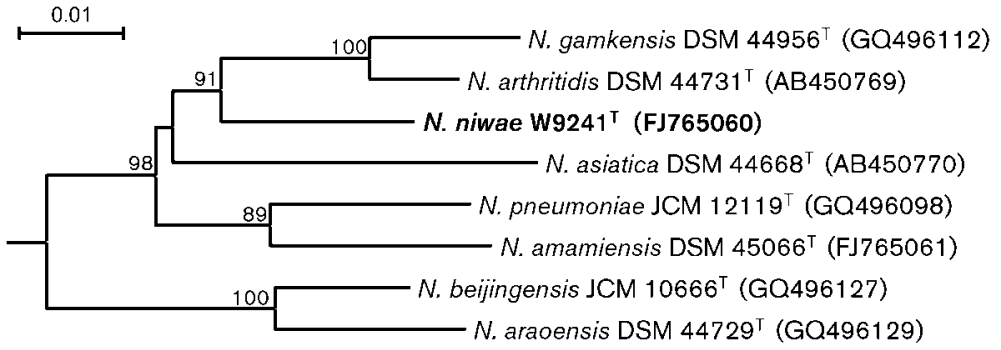

Fig. 2. Phylogenetic tree, based on gyrB gene sequences, showing the relationships of strain W $9241^{\top}$ and a few closely related Nocardia species. For construction details, see legend of Fig. 1. Bar, 0.01 substitutions per nucleotide position. The full tree from which this area is taken is available as Supplementary Fig. S2 in IJSEM Online.

The mean DNA-DNA relatedness values between strains W8027, W8681, W9071 and $W 9241^{\mathrm{T}}$ ranged from 86 to $89 \%$. The levels of DNA-DNA relatedness between strain W9241 ${ }^{\mathrm{T}}$ and $N$. beijingensis JCM $10666^{\mathrm{T}}, N$. araoensis DSM $44729^{\mathrm{T}}, N$. arthritidis DSM $44731^{\mathrm{T}}$, N. amamiensis DSM $45066^{\mathrm{T}}$ and $N$. asiatica DSM $44668^{\mathrm{T}}$ were $47 \%, 46 \%, 44 \%$, $32 \%$ and $20 \%$, respectively. These values were below the $70 \%$ cut-off recommended by Wayne et al. (1987) for species delineation.

As a result of the polyphasic approach applied to our taxonomic investigation, we found that the four strains isolated from pulmonary sources represented a novel species of the genus Nocardia. Phenotypic analysis showed that the new strains showed differential characteristics of growth at $45{ }^{\circ} \mathrm{C}$ and L-rhamnose utilization (except for strain W9071) from related species of the genus Nocardia. The results of the phylogenetic analysis of $16 \mathrm{~S}$ rRNA and gyrB gene sequences and DNA-DNA hybridization demonstrated that these strains represented a distinct entity for which we propose the name Nocardia niwae sp. nov.

\section{Description of Nocardia niwae sp. nov.}

Nocardia niwae (ni'wa.e. N.L. gen. n. niwae of Niwa, named in honour of Dr Hidekazu Niwa, our Japanese colleague; a veterinarian and microbiologist).

Aerobic, Gram-positive, weakly acid-fast, non-motile actinomycete, forming orange-coral-coloured aerial and substrate hyphae on Middlebrook 7H11 media. Utilizes and produces acid from D-glucose, glycerol, L-rhamnose, sucrose and trehalose, but does not utilize adonitol, Larabinose, cellobiose, dulcitol, i-erythritol, D-fructose, Dgalactose, myo-inositol, lactose, maltose, D-mannitol, mannose, melibiose, raffinose, salicin, D-sorbitol or $\mathrm{D}$ xylose. Utilizes citrate as sole carbon source, but not acetamide as a carbon and nitrogen source. Grows in the presence of lysozyme, reduces nitrate, but has no arylsulfatase activity. Hydrolyses urea, but does not hydrolyse adenine, aesculin, casein, hypoxanthine, tyrosine or xanthine. Grows at 25,35 and $45{ }^{\circ} \mathrm{C}$.

The type strain, W9241 ${ }^{\mathrm{T}}\left(=\mathrm{DSM} 45340^{\mathrm{T}}=\right.$ CCUG $57756^{\mathrm{T}}$ ), was isolated from the lung tissue of a 60-year-old male in the state of Florida, USA. The $\mathrm{G}+\mathrm{C}$ value of the DNA for the type strain is $68.5 \mathrm{~mol} \%$.

\section{Acknowledgements}

We would like to thank Jean Euzéby for his advice and collaboration in the naming of this organism. We acknowledge the assistance of Oliver Clay, Ainsley Nicholson and Corey Franzen at the Division of Foodborne, Bacterial, and Mycotic Diseases Genomics Unit, CDC.

\section{References}

Baba, T., Nishiuchi, Y. \& Yano, I. (1997). Composition of mycolic acid molecular species as a criterion in nocardial classification. Int J Syst Bacteriol 47, 795-801.

Berd, D. (1973). Laboratory identification of clinically important aerobic actinomycetes. Appl Microbiol 25, 665-681.

Boiron, P., Provost, F., Chevrier, G. \& Dupont, B. (1992). Review of nocardial infections in France 1987 to 1990. Eur J Clin Microbiol Infect Dis 11, 709-714.

Brenner, D. J., McWhorter, A. C., Knutson, J. K. \& Steigerwalt, A. G. (1982). Escherichia vulneris: a new species of Enterobacteriaceae associated with human wounds. J Clin Microbiol 15, 1133-1140.

Brown-Elliott, B. A., Brown, J. M., Conville, P. S. \& Wallace, R. J., Jr (2006). Clinical and laboratory features of the Nocardia spp. based on current molecular taxonomy. Clin Microbiol Rev 19, 259-282.

Conville, P. S. \& Witebsky, F. G. (2007). Nocardia, Rhodococcus, Gordonia, Actinomadura, Streptomyces, and other aerobic actinomycetes. In Manual of Clinical Microbiology, 9th edn, pp. 515-542. Edited by P. R. Murray, E. J. Baron, J. H. Jorgensen, M. L. Landry \& M. A. Pfaller. Washington, DC: American Society for Microbiology.

Goodfellow, M. (1998). Nocardia and related genera. In Topley and Wilson's Microbiology and Microbial Infections, 9th edn, vol. 2, Systematic Bacteriology, pp. 463-489. Edited by A. Balows \& B. I. Duerden. London: Arnold.

Goodfellow, M. \& Maldonado, L. A. (2006). The families Dietziaceae, Gordoniaceae, Nocardiaceae and Tsukamurellaceae. In The Prokaryotes, 3rd edn, vol. 3, pp. 843-888. Edited by M. Dworkin, S. Falkow, E. Rosenberg, K. H. Schleifer \& E. Stackebrandt. New York: Springer.

Gordon, R. E., Barnett, D. A., Handerhan, J. E. \& Pang, C. H.-N. (1974). Nocardia coeliaca, Nocardia autotrophica, and the nocardin strain. Int J Syst Bacteriol 24, 54-63.

Kämpfer, P., Buczolits, S., Jäckel, U., Grün-Wollny, I. \& Busse, H.-J. (2004). Nocardia tenerifensis sp. nov. Int J Syst Evol Microbiol 54, 381383.

Klatte, S., Kroppenstedt, R. M. \& Rainey, F. A. (1994). Rhodococcus opacus sp. nov., an unusual nutritionally versatile Rhodococcusspecies. Syst Appl Microbiol 17, 355-360. 
Kroppenstedt, R. M. (1982). Separation of bacterial menaquinones by HPLC using reverse phase (RP18) and a silver loaded ion exchanger as stationary phases. J Liq Chromatogr 5, 2359-2367.

Kroppenstedt, R. M. (1985). Fatty acid and menaquinone analysis of actinomycetes and related organisms. In Chemical Methods in Bacterial Systematics (SAB Technical Series no. 20), pp. 173-199. Edited by M. Goodfellow \& D. E. Minnikin. London: Academic Press.

Loeffelholz, M. J. \& Scholl, D. R. (1989). Method for improved extraction of DNA from Nocardia asteroides. J Clin Microbiol 27, $1880-1881$.

Mesbah, M., Premachandran, U. \& Whitman, W. B. (1989). Precise measurement of the $\mathrm{G}+\mathrm{C}$ content of deoxyribonucleic acid by high-performance liquid chromatography. Int J Syst Bacteriol 39, 159-167.

Minnikin, D. E., Patel, P. V., Alshamaony, L. \& Goodfellow, M. (1977). Polar lipid composition in the classification of Nocardia and related bacteria. Int J Syst Bacteriol 27, 104-117.

Minnikin, D. E., O’Donnell, A. G., Goodfellow, M., Alderson, G., Athalye, M., Schaal, A. \& Parlett, J. H. (1984). An integrated procedure for the extraction of bacterial isoprenoid quinones and polar lipids. J Microbiol Methods 2, 233-241.

Morey, R. E., Galloway, R. L., Bragg, S. I., Steigerwalt, A. G., Mayer, L. W. \& Levett, P. N. (2006). Species-specific identification of Leptospiraceae by $16 \mathrm{~S}$ rRNA gene sequencing. J Clin Microbiol 44, 3510-3516.

NCCLS (2003). Susceptibility testing of mycobacteria, nocardiae and other aerobic actinomycetes. Approved standard M24-A. Wayne, PA: National Committee for Clinical Laboratory Standards.
Rhuland, L. E., Work, E., Denman, R. F. \& Hoare, D. S. (1955). The behaviour of the isomers of $\alpha, \varepsilon$-diaminopimelic acid on paper chromatograms. J Am Chem Soc 77, 4844-4846.

Roth, A., Andrees, S., Kroppenstedt, R. M., Harmsen, D. \& Mauch, H. (2003). Phylogeny of the genus Nocardia based on reassessed $16 \mathrm{~S}$ rRNA gene sequences reveals underspeciation and division of strains classified as Nocardia asteroides into three established species and two unnamed taxons. J Clin Microbiol 41, 851-856.

Sasser, M. (1990). Identification of bacteria by gas chromatography of cellular fatty acids. USFCC Newsl 20, 16.

Shen, F.-T., Lu, H. L., Lin, J. L., Huang, W. S., Arun, A. B. \& Young, C. C. (2006). Phylogenetic analysis of members of the metabolically diverse genus Gordonia based on proteins encoding the gyrB gene. Res Microbiol 157, 367-375.

Stackebrandt, E., Frederiksen, W., Garrity, G., Grimont, P. A., Kämpfer, P., Maiden, M. C., Nesme, X., Rossella-Mora, R., Swings, J. \& other authors (2002). Report of the ad hoc committee for the re-evaluation of the species definition in bacteriology. Int $J$ Syst Evol Microbiol 52, 1043-1047.

Tamura, K., Dudley, J., Nei, M. \& Kumar, S. (2007). MEGA4: Molecular evolutionary genetics analysis (MEGA) software version 4.0. Mol Biol Evol 24, 1596-1599.

Wayne, L. G., Brenner, D. J., Colwell, R. R., Grimont, P. A. D., Kandler, O., Krichevsky, M. I., Moore, L. H., Moore, W. E. C., Murray, R. G. E. \& other authors (1987). International Committee on Systematic Bacteriology. Report of the ad hoc committee on reconciliation of approaches to bacterial systematics. Int $J$ Syst Bacteriol 37, 463-464. 